\title{
Integrated Procedure for Environmental Flow Assessment in Rivers
}

\author{
Francisco Godinho • Sérgio Costa • Paulo Pinheiro • \\ Filipa Reis • António Pinheiro
}

Received: 15 November 2013 / Accepted: 21 January 2014 / Published online: 24 April 2014

(C) Springer International Publishing Switzerland 2014

\begin{abstract}
To mitigate the ecological impacts of dams on rivers, restoration projects are focusing on implementing environmental flow regimes to improve ecosystems' health. In Europe, the water requirements for river ecosystem improvement are receiving increasing attention in water supply planning, namely within the Water Framework Directive, which provides a general framework for river protection. Because the protection or restoration of environmental flows necessarily entails trade-offs with other potential water uses, it is important that the water requirements of a river ecosystem are defined using best-available scientific knowledge. Several methodologies have been used to formulate environmental flow requirements downstream of dams in European rivers, ranging from simple use of hydrological records to establish minimum and flushing flows, to modelling procedures linking changes in river discharge with ecological responses. However, no set of techniques or conceptual framework methodology has been accepted without reservations. This paper describes an integrated procedure for establishing environmental flow regimes in rivers and presents the results of preliminary applications in Portugal. The procedure comprises several steps, i.e., collection of background information, selection and sampling of representative river reaches, formulation of environmental flow regimes by means of different methods, field evaluation of the different flow regimes by a multi-disciplinary team of scientists, proposal of an environmental flow regime, monitoring and adaptation, that can be tailored according to available time and financial resources.
\end{abstract}

Keywords Environmental flows · River restoration - Integrated process - WFD - River regulation · Iberian rivers

F. Godinho $(\bowtie) \cdot \mathrm{S}$. Costa $\cdot$ P. Pinheiro $\cdot$ F. Reis

AQUALOGUS - Engenharia e Ambiente, Lda., Alameda dos Oceanos, Edifício Mar do Oriente, Lote 1.07.1 AN 2.4 Parque das Nações, 1990-208 Lisboa, Portugal

e-mail: fgodinho@aqualogus.pt

F. Godinho

e-mail: geral@aqualogus.pt

A. Pinheiro

CEHIDRO, Instituto Superior Técnico, Universidade de Lisboa, Lisboa, Portugal 


\section{Introduction}

Human regulation of river flows is a global phenomenon that has provided many societal benefits, namely for irrigation, urban supply and hydropower generation, but has also caused ecological damage and loss of ecosystem services (García de Jalón et al. 1992).

To mitigate the impacts of flow regulation, river restoration projects are presently focusing on implementing environmental flow regimes to improve fluvial ecosystems previously degraded (Arthington and Pusey 2003). In addition, water resources planners address the water requirements of river ecosystems proactively by reserving some portion of river flows for ecosystem support within new water development projects.

In Europe, the water requirements of river ecosystems are receiving increasing attention in water supply planning, namely within the Water Framework Directive (WFD) of the European Union, which provides general mechanisms for river protection to return damaged water bodies to good ecological status, including the provision of environmental flows capable of sustaining biological elements and river processes (e.g., Postel and Richter 2003; Hirji and Davis 2009). Because the protection or restoration of environmental flows necessarily entails trade-offs with other potential uses of water, it is very important that the water requirements of a river ecosystem are defined using best-available scientific information and knowledge.

To date, several techniques have been used to assess environmental flow requirements in regulated rivers, ranging from simple use of the hydrological data to establish minimum flows, to modelling procedures linking changes in river discharge with ecological responses (Tharme 2003). Notwithstanding, no set of techniques or conceptual framework methodology has been globally accepted and results of different methods are often contradictory (Jowett 1997). Even when applying methods which consider biological data of different species, with different life stages, the results usually show that it is not possible to permanently satisfy the needs of those species and life stages. So, at the end, pragmatic decisions must be taken on the different mean monthly discharges of the environmental flow regime for each case (Acreman and Ferguson 2010).

Because of the inherent complexity of ecosystem responses to variable flow regimes, the process of determining environmental flows should be considered as an iterative process. Accordingly, each river restoration project must be regarded as an experiment to be monitored and carefully evaluated, enabling scientific refinement of environmental flow recommendations over time (Richter et al. 2006; Davies et al. 2013).

The present study focuses on the Iberian Peninsula, which like other Mediterranean climate regions, has a long history of human settlement and consequent use of water resources. After briefly reviewing methods applied thus far in Iberia for environmental flow evaluation, this paper describes an adaptive, inter-disciplinary process for developing environmental flow recommendations for rivers and streams. The procedure has been designed for use in different water management activities, including flow restoration projects, and can be tailored according to available time and resources for determining the environmental flow needs of rivers and streams.

\section{Methodologies Used for Environmental Flow Assessment in Iberian Rivers}

River discharge is highly variable in Iberia, both intra and inter-annually. Most river runoff (up to $95 \%$ ) is concentrated on a wet semester (October-March) and interannual variation in total discharge could reach ratios above 100 to 1 (Daveau 1977). Such extreme hydrological conditions, including both occasional floods and extreme droughts, 
naturally shape fluvial ecology, rendering a high temporal dynamism in the available aquatic habitat (Benejam et al. 2010).

As elsewhere, several methodologies have been used in Iberia since 1980 to establish environmental flow requirements, including, sensu Tharme (2003), hydrological, hydraulic rating and habitat simulation methods. Hydrological methodologies are the simplest set of techniques, where long-term hydrological data series are analysed to characterize the flow regimes. These desktop methods were among the first used in Iberia, initially simply to establish minimum constant flows intended to maintain minimum river health, although at an unknown ecological status (sensu WFD). Minimum environmental flows were derived as a proportion of the natural flow, commonly with values between 3 and $5 \%$ of the average mean annual flow. Such flow regimes were usually derived on an annual basis, though later were used in a seasonal or monthly basis, trying to mimic natural flow variation.

Some hydrological methods have been specifically developed for Iberia and include the Basic Flow Method (Palau 1994; Palau and Alcázar 1996) and the Portuguese Water Authority method (Alves and Bernardo 2002). The first method proposed an environmental flow regime based on a key-hydrological indicator, the baseflow $\left(\mathrm{Q}_{\mathrm{b}}\right)$, considered to be the absolute minimum flow that should be circulating within the river at any given time. Its calculation is based on the statistical analysis of irregularities of the hydrological series of daily mean flows (see Palau and Alcázar 1996; Alcázar et al. 2008). From Qb, other indicators are obtained, including maintenance flow, bankfull flow and maximum rate of flow change.

Since 2002, the Portuguese Water Authority has used a hydrological method that includes distinct percentiles from a flow duration curve, for different periods of the year (Alves and Bernardo 2002). Different periods were considered to have specific ecological characteristics and encompass the period of fish migration and reproduction and the summer dry season, when biota survives in shrinking river pools. Moreover, the methodology proposes specific exceedance percentiles for each one of the three homogeneous hydrological regions that were defined.

Hydraulic rating methodologies use changes in hydraulic parameters (e.g., maximum depth and wetted perimeter), usually measured across river cross sections, as a surrogate for habitat factors known or assumed to limit target biota survival. Environmental flows are determined from a plot of the hydraulic parameter(s) against discharge, commonly by identifying curve breakpoints where significant reductions of the derivative of habitat availability with respect to river discharge occur. Selected approaches continue to be applied in Iberia, namely the Wetted Perimeter method (e.g., Oliveira et al. 2004).

Portela (2006) presented a method, supported both by hydrologic and hydraulic criteria, aiming to define environmental flows in Southern Portugal. The hydrologic criterion accounts for the water scarcity and the temporal irregularity of the natural hydrologic regime, whereas the hydraulic criterion accounts for the geometry of the river cross sections or river reaches. Bernardo and Alves (1999) also proposed a methodology for ecological flow assessment in Iberian rivers that considers the summer low flow conditions as the major environmental constraint, which includes the following steps: (i): characterization of fish assemblages at the studied river; (ii) analysis of aerial photography from several hydrological years to identify persistent summer pools in distinct hydrological conditions; (iii) use of a precipitation-runoff model to analyse the hydrological regime during the years of the aerial photos; (iv) based on the runoff data, definition of the ecological flow that should allow the persistence of the summer pools in conditions considered favourable for the fish fauna.

Habitat simulation methods are based on the explicit integration of river bed and flow characteristics, and of biological response data. Flow-related changes in physical microhabitat are numerically modelled, typically using data on depth, velocity and substratum composition, 
collected at multiple cross sections within each representative river reach. Simulated data on available habitat is linked with information on the range of habitat conditions used by target species (usually fish) or life-history stages, commonly using habitat suitability index curves (e.g., Santos and Ferreira 2008; Boavida et al. 2011). The outputs, in the form of habitatdischarge curves for specific biota, are used to derive environmental flows. Several habitat simulation-modelling programs have been used (e.g., PHABSIM ${ }^{\mathrm{TM}}$, Stalnaker et al. 1994; River 2D ${ }^{\mathrm{TM}}$, Steffler 2000).

Despite the several methodologies used so far in the Iberian Peninsula for environmental flow assessment, no single method has been recognised without reservations. More complex methodologies (e.g., habitat simulation) may require unavailable time and financial resources, whereas other, more expedite approaches, have been criticized based on the lack of ecological justification for the flow indicators adopted (most hydrological methods). For example, the baseflow method often results in zero flow in southern Iberian rivers, whereas the Portuguese Water Authority method may result in very high flows (Portela 2007).

\section{The Proposed Procedure}

In order to overcome the limitations referred above, a procedure inspired by the 'holistic' methodologies (Arthington and Zalucki 1998; Tharme 2003; Arthington et al. 2004) was developed. In short, the procedure comprises seven sequential steps (Fig. 1) and its major feature encompasses the application of different methods for ecological flow assessment that are confronted in the field by a multi-disciplinary team of scientists.

The first step includes the definition of the study area and collection of background information. The study area is defined based on the dam location (existing or planned) within the catchment and its relative location to other dams. If a large dam (height $>15 \mathrm{~m}$ ) without fish passage exists downstream, then that dam marks the downstream limit of the study area. If no dam exists downstream, the study area is limited by a zone of ecological transition, such as the confluence with a major tributary or with the main river or the upstream limit of the estuary. At this initial step, interested parties are engaged, including scientists, water agencies (at the national or regional level) and stakeholders (including the owner of the existing or planned dam and other downstream stakeholders). The team collects available background information, including topographic, hydrological and ecological data (biotic assemblages, water quality and hydromorphological characteristics, sensu WFD). Particular attention is given to the hydrological regime analysis, including both natural and altered flow regimes. To characterize the natural flow regime, long-term daily flow data are obtained directly from gauging stations or from rainfall-runoff relationships (e.g., Vaze et al. 2012), whereas the altered flow regime is based on the dam operation data (either existing or planned). From the flow data, several hydrologic indicators are derived to characterize the flow regime, such as the mean daily discharge and the mean monthly flows.

The second step entails the selection and ecological sampling of representative river reaches downstream of the dam. The number of sampling reaches varies with the extension of the study area and the hydromorphological diversity of the river segment, as well as with available budget and time constraints. Sampling includes, following the WFD, biotic, hydromorphological and water quality elements. The ecological integrity (or status, sensu WFD) is evaluated at each river reach by using indices of ecological integrity developed within the context of the WFD. The ecological status assesses the degree of deviation of the ecological characteristics from reference/pristine conditions, i.e., the conditions that characterize a similar river without human interference. 


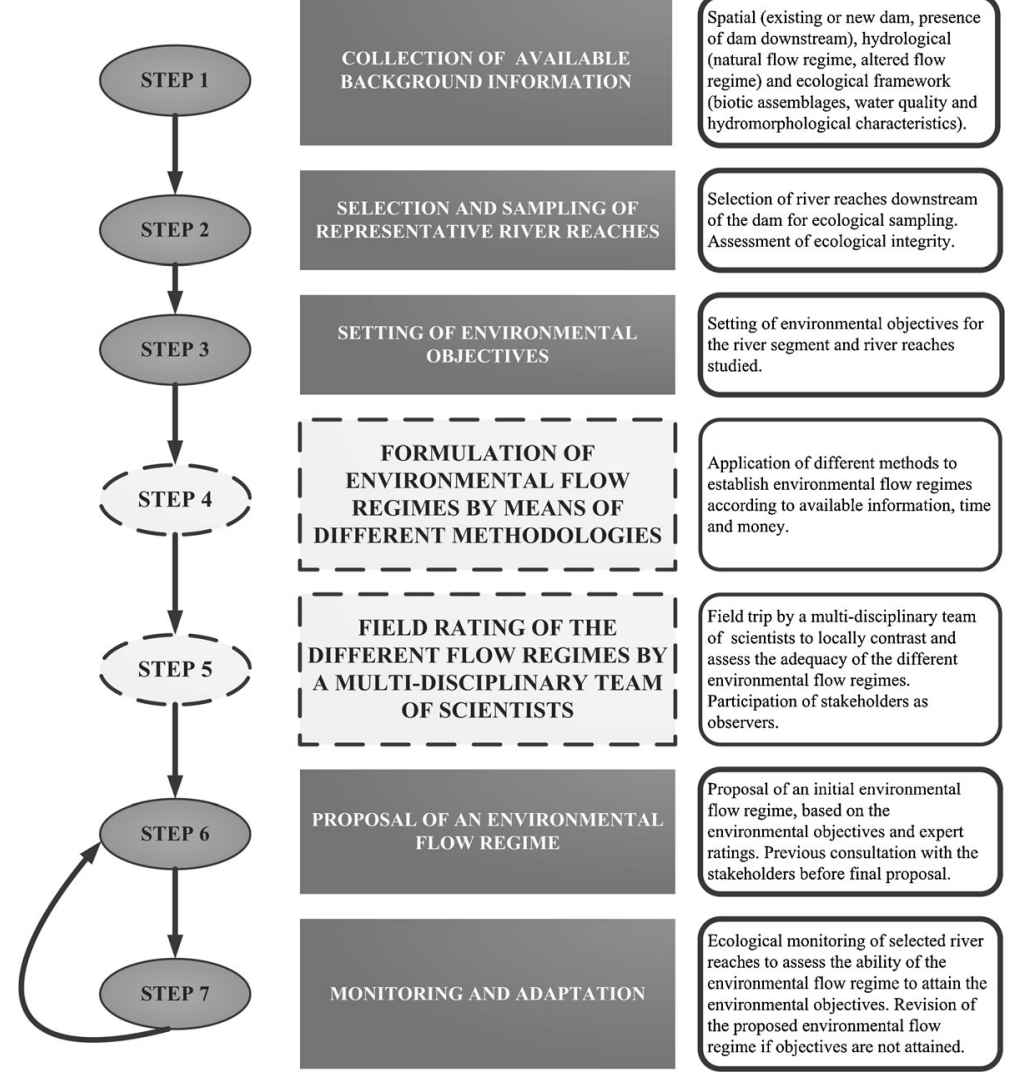

Fig. 1 General framework of the procedure developed for environmental flow assessment in rivers

The third step is closely linked to the second one, with the setting of the environmental objectives. This setting is globally based on the WFD and varies according to the ecological sensitivity of the area and the acceptable degree of river alteration. According to the WFD, environmental objectives for river water bodies are generally attaining good ecological status, i.e., a small amount of deviation from pristine conditions. Notwithstanding, river segments downstream of dams can be classified as heavily modified water bodies (HMWB), if human alterations are such that it is technically and economically unfeasible to restore river ecosystems to good ecological status. In those cases, good ecological potential, defined as the higher ecological status attainable after incorporating some of the impacts of flow regulation, becomes the environmental objective.

The next step encompasses the formulation of environmental flow regimes using different methodologies. At least, one hydraulic method that allows the conversion of summary hydrological statistics to information on local hydraulic conditions, such as the wetted perimeter, must be used, together with other methods that may include habitat simulation methodologies, its number depending on available information, time and/or financial resources. The results of the different methods must be summarized for several cross sections within the study area, usually incorporating information like the mean and maximum discharge values obtained by each method used, as well as indicators of the natural flow conditions (e.g., average daily flow and average monthly flow) (Fig. 2). For this purpose, a hydraulic model 

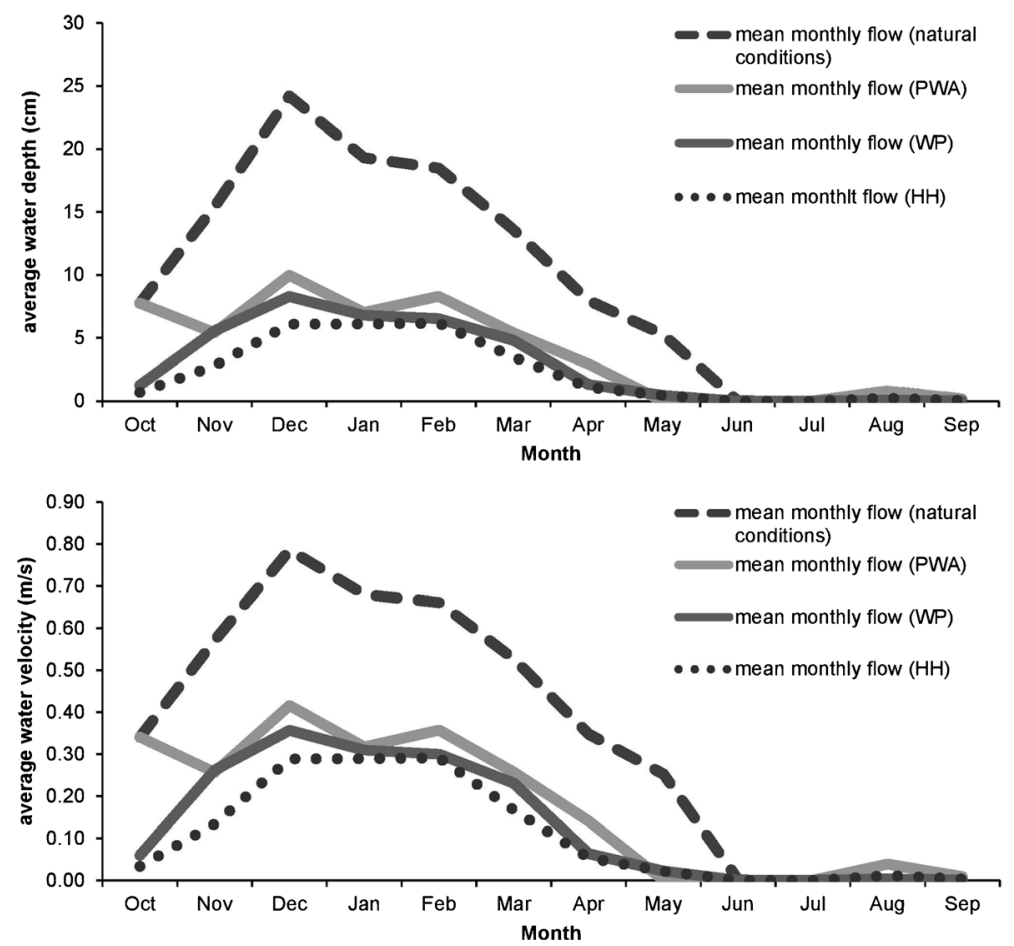

Fig. 2 Average water depth and velocity associated with mean natural monthly flows and average monthly environmental ecological flows as assessed with different methods in Amoreiras stream cross section. Regimes derived from the methods applied: $W P$ wetted perimeter method, $P W A$ Portuguese Water Authority method, $H H$ Portela method

must be calibrated and used to compute the different flow depths for each cross section for the different discharges considered. For methods that generate single flow estimates (e.g., wetted perimeter), a monthly ecological regime of flow is established by concentrating on the ecological needs during critical summer months and giving a flow fluctuation proportionally to natural flow regime for the remaining months (García de Jalón 2003).

The fifth step includes the rating of the different flow regimes by a multidisciplinary team of scientists, typically including hydrology, hydraulics, geomorphology, macrophytes, benthic macroinvertebrates and fish scientists. To implement the process, during the field trip, each cross section is observed in detail by the scientists. For the field trip, cross section diagrams, showing stage heights and associated discharges are prepared, as well as rulers depicting the depths associated with each discharge to assist the visual perception of the different water levels (Fig. 3). The maximum and average discharges obtained by each method are presented on the rulers, in different shades, within the same colour.

The scientists locally contrast and assess the adequacy of the different environmental flow regimes, on a monthly basis. The stakeholders also take part in the field visit, as observers. Later, written reports are independently produced by each scientist, with propositions, on a monthly basis, of the recommended flows, which take into account the values of the different methods applied, the natural flow conditions and the field observations. Other considerations, e.g., regarding flushing floods, are also noted for office analysis. 


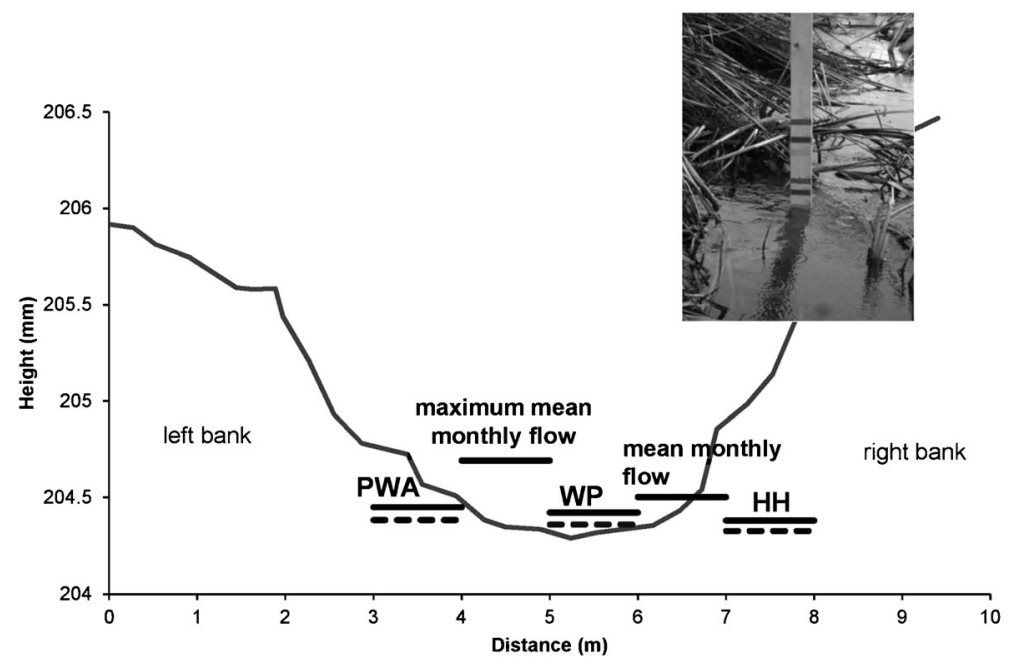

Fig. 3 Example of stream cross section plot made for use in the scientists field trip, with notable flows and associated depth. Natural flow: mean annual flow is the average of the daily flows in the period of record (one or more years) and maximum mean monthly flow is the average flow for the month with the highest discharge (December). Flows derived from the methods applied: WP wetted perimeter, $P W A$ Portuguese Water Authority method, $H H$ Portela method. For each method the mean monthly flow (solid line) and the maximum mean monthly flow (dashed line) are presented. An example of a ruler presenting the depths associated with notable flows and used in the field assessment is also presented

The sixth and final step is the proposal of an environmental flow regime, on a monthly basis, that is based on the environmental objectives and scientists ratings. If scientific ratings diverge regarding particular flows, conciliatory propositions are made by the team leader in order to reach consensus. If agreement is not possible, the environmental flow recommended by the majority of scientists is selected. The environmental flow regime is subjected to a previous consultation by the stakeholders before final proposal and implementation. Finally, the environmental flow regime is implemented and monitored.

Ecological monitoring of selected river reaches is required to assess the ability of the environmental flow regime to attain the environmental objectives previously established for the area. After initial ecological monitoring (5-7 years), and if objectives are not met, the proposed environmental flow regime must be revised by scientists, with a previous consultation with the stakeholders.

\section{Study Cases}

The described procedure has been applied to Portuguese rivers from 2008 onwards (Fig. 4), in studies with different time frames and budgets, as well as with diverse spatial, hydrological and ecological contexts (Table 1). As a consequence, the methods selected for the determination of environmental flow regimes varied among the studies. Overall, the scientists were able to reach consensus upon the environmental flows proposed, balancing results obtained by the different methods. 


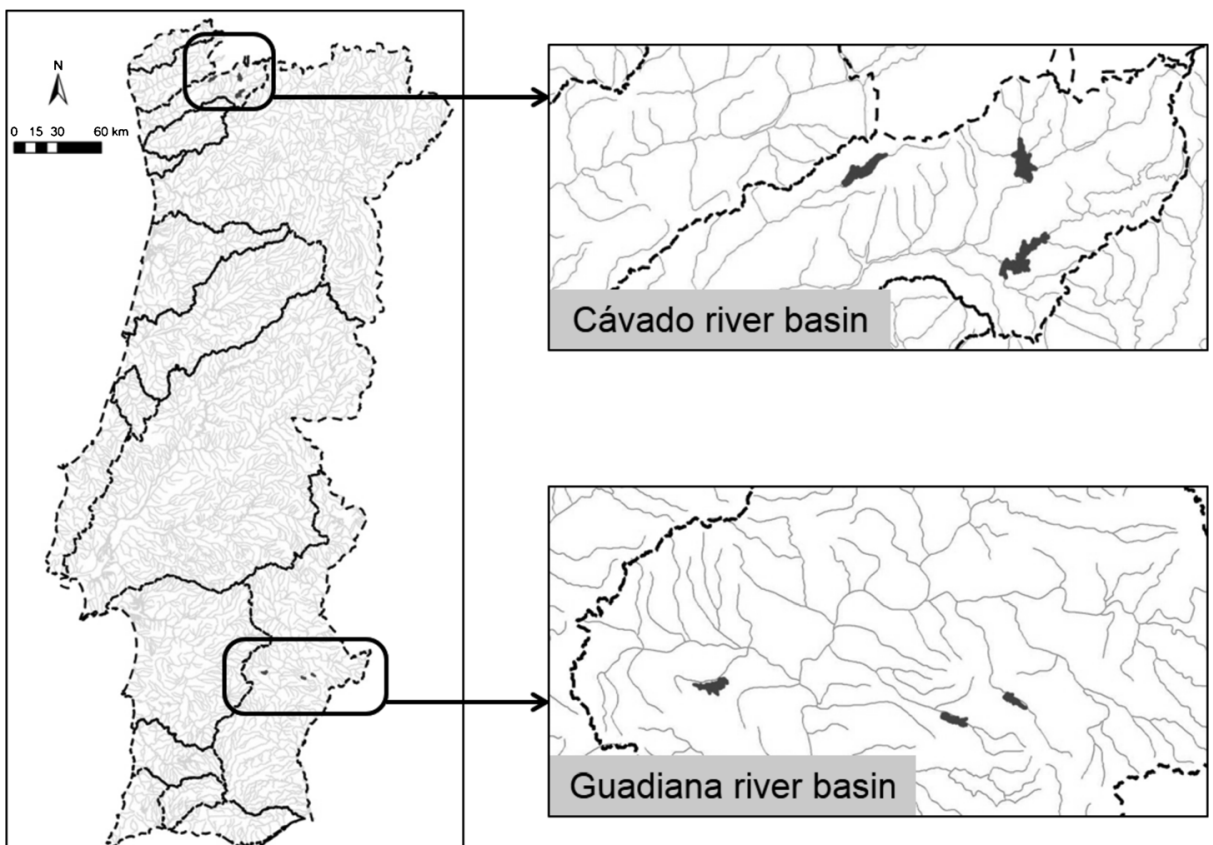

Fig. 4 Location of the rivers studied in Portugal for the establishment of environmental flow regimes with the described procedure

The proposed environmental flow regimes presented a monthly basis and varied from dry to wet years. Moreover, flushing flows required for maintaining the channel structures (by removing sediments and excessive riparian vegetation) were also proposed. Such flows were also considered important to reduce the abundance of non-native fish species, mostly adapted to slow flowing waters, thus reducing their invasive capacity (Godinho et al. 2000).

In the temporary southern rivers, where new dams were constructed, the proposed environmental flow regimes began to be implemented and their effects upon the fluvial ecosystem are currently being monitored. Notwithstanding, the area will concurrently undergo an increase in irrigation farming in association with irrigation, which may limit the efficacy of the environmental flows to attain good ecological status (Matono et al. 2013). In the permanent northern rivers, new devices are being constructed in the old dams to allow the release of the environmental flows proposed that, subsequently, will also be monitored and evaluated.

\section{Discussion}

The proposed procedure strongly deals with the integration of results obtained with different environmental flow assessment methods that are further compared with natural flow conditions. Such integration is made by a multi-disciplinary team of scientists, as it is common in holistic methodologies, but unlike many procedures that rely only on desktop rating of the environmental flows considered, includes a field-based ecological interpretation of the different flow regimes, at selected river cross sections.

The field interpretation is assisted by cross section diagrams showing stage heights and associated discharges and rulers produced for specific cross sections depicting the depths 
Table 1 General features of some specific applications of the integrated procedure developed for Iberian rivers

\section{General context}

Study objective

Available time (months)

Spatial context

River basin

Rivers studied

Catchment area of the dam $\left(\mathrm{km}^{2}\right) \quad 70-360$

Hydrological context (natural conditions)

\section{River type}

Average annual flow $\left(\mathrm{hm}^{3}\right)$

Average mean daily flow $\left(\mathrm{m}^{3} / \mathrm{s}\right)$

Average monthly flow $\left(\mathrm{m}^{3} / \mathrm{s}\right)$

Ecological context

Fish assemblages

\section{Riparian vegetation}

Other anthropogenic stressors apart from flow regulation

Methodological procedure

Environmental objectives

Methods applied

\section{Scientists participation}

\section{General results}

Environmental flow established

\section{Consideration of distinct monthly flow values, mimicking the natural flow variability of each river}

Consideration of different values for normal, wet and dry years

Consideration of flushing flows Final remarks
Cávado

Cávado, Rabagão and Homem

Restoration of river ecosystem health downstream of existing hydroelectric dams (constructed from 1951 to 1972 )

10

Permanent

47.3 to 98.0

4.1 to 8.6

0.38 (August) to 19.1 (January)

Permanent presence of fishes including intolerant salmonids (brown trout, Salmo trutta fario)

Abundant

None

Good ecological potential (sensu WFD)

Baseflow method, Portuguese National Water Authority method, Wetted Perimeter, fish habitat simulation techniques

Hydrology, hydromorphology, macrophytes, benthic macroinvertebrates and fish

Reached by consensus, varying from 5 to $13 \%$ of the total annual flow in natural conditions

Yes

Yes

Yes

The release of the environmental flows proposed will require the construction of specific devices in the existing dams.
Maintaining river ecosystem health downstream of projected irrigation dams

$<5$

Guadiana

São Pedro, Brenhas and Amoreiras

30-45

Temporary

3.2 to 4.5

0.10 to 0.14

0 (August) to 0.57 (December)

Occasional presence of fishes, during periods of higher flow. Fish assemblages composed mostly of tolerant small sized specimens

Variable, often missing

Agriculture

Good ecological status (sensu WFD)

Baseflow method, Portela method, Portuguese National Water Authority method, Wetted Perimeter

Hydrology, hydromorphology, macrophytes and fish

Reached by consensus, varying from 12 to $15 \%$ of the total annual flow in natural conditions

Yes

Yes

Yes

The ecological results of the environmental flow regime proposed could be constrained by the influence of intensive agriculture activities. 
associated with each discharge; it also expands the field evaluation of different trial environmental flow releases from dams performed in Australia by Swales and Harris (1995) to situations where such flow releases are not possible, i.e., rivers with projected dams or with old dams lacking adequate outflow devices. The comparative visualization of the flow heights obtained from different methods in particular river cross sections was considered extremely helpful by the scientists at reaching agreement on the environmental flows to be released.

The possible use of different individual methods for environmental flow assessment in the described procedure also allows tailoring according to the time and budget available in a particular study. In addition, individual methods could be selected based on their adaptation for the specific river basin or region under analysis, thus making the procedure applicable to any small and medium-size river, where the use of the ruler is possible.

Moreover, the procedure clearly links with the WFD, through the setting of environmental objectives and by relying on ecological monitoring and adaptation, something that has been missing in the establishment of adequate environmental flow regimes worldwide (Davies et al. 2013). Given the gaps in knowledge still existing about the ecological functioning of most rivers for which environmental flows are to be established, only the ecological monitoring of the regulated reach-HMWB - will allow the evaluation of their adequacy for attaining the environmental objectives and its subsequent refinement.

Acknowledgments An initial version of this paper was presented at the 8th International Conference of the EWRA in Porto, Portugal, June 26-29, 2013.

\section{References}

Acreman MC, Ferguson JD (2010) Environmental flows and the European Water Framework Directive. Freshw Biol 55:32-48. doi:10.1111/j.1365-2427.2009.02181.x

Alcázar J, Palau A, Vega-García A (2008) Neural net model for environmental flow estimation at the Ebro River Basin, Spain. J Hydrol 349:44-55. doi:10.1016/j.jhydrol.2007.10.024

Alves MH, Bernardo JM (2002) Environmental flows in Portugal. INAG, Ministério das Cidades, Ordenamento do Território e Ambiente, Lisboa, Portugal, (In Portuguese)

Arthington AH, Pusey BC (2003) Flow restoration and protection in Australian rivers. River Res Appl 19:377395. doi:10.1002/RRA.745

Arthington AH, Zalucki JM (Eds) (1998) Comparative evaluation of environmental flow assessment techniques: review of methods. LWRRDC Occasional Paper No. 27/98, Camberra

Arthington AH, Tharme RE, Brizga SO, Pusey BJ, Kennard MJ (2004) Environmental flow assessment with emphasis on holistic methodologie. In: Wecomme R, Petr T (eds) Proceedings of the Second International Fish Synposium on the Management of Large Rivers for Fisheries, Volume II. FAO Regional Office for Asia and the Pacific, Bangkok, Thailand. RAP Publication, pp 37-65

Benejam L, Angermeier PL, Munné A, García-Berthou E (2010) Assessing effects of water abstraction on fish assemblages in Mediterranean streams. Freshw Biol 55:628-642. doi:10.1111/j.1365-2427.2009.02299.x

Bernardo JM, Alves MH (1999) New perspectives for ecological flow determination in semiarid regions: a preliminary approach. Regul River 15:221-229. doi:10.1002/(SICI)1099-1646(199901/06)15:1/ $3<221:: A I D-R R R 537>3.0$. CO;2-A

Boavida I, Santos JM, Pinheiro NA, Ferreira MT (2011) Fish habitat availability simulations using different morphological variables. Limnetica 30:393-404

Daveau S (1977) Répartition et rythme des précipitations au Portugal. Memórias do Centro de Estudos Geográficos, Lisboa

Davies PM, Naiman RJ, Warfe DM, Pettit NE, Arthington AH, Bunnc SE (2013) Flow-ecology relationships: closing the loop on effective environmental flows. Mar Freshw Res. doi:10.1071/MF13110

García de Jalón DG (2003) The Spanish experience in determining minimum flow regimes in regulated streams. Can Water Resour J 28:185-198. doi:10.4296/cwrj2802185 
García de Jalón D, González del Tanágo M, Casado C (1992) Ecology of regulated rivers in Spain: an overview. Limnetica 8:161-166

Godinho FN, Ferreira MT, Santos JM (2000) Variation in fish community composition along an Iberian river basin from low to high discharge: relative contributions of environmental and temporal variables. Ecol Freshw Fish 9:20-29. doi:10.1034/j.1600-0633.2000.90104.x

Hirji R, Davis R (2009) Environmental Flows in water resources policies, plans, and projects. Case studies. The International Bank for Reconstruction and Development/THE WORLD BANK

Jowett IG (1997) Instream flow methods. A comparison of approaches. Regul River 13:115-127. doi:10.1002/ (SICI)1099-1646(199703)13:2<115::AID-RRR440>3.0.CO;2-6

Matono P, Sousa D, Ilhéu M (2013) Effects of land use intensification on fish assemblages in Mediterranean climate streams. Environ Manag 52:1213-1229. doi:10.1007/s00267-013-0152-3

Oliveira JM, Ferreira MT, Pinheiro AN, Bochechas JH (2004) A simple method for assessing minimum flows in regulated rivers: the case of sea lamprey reproduction. Aquat Conserv 14:481-489. doi:10.1002/aqc.634

Palau A (1994) Los mal llamados caudales "ecológicos". Bases para una propuesta de cálculo. Obra Pública 28: $84-95$

Palau A, Alcázar J (1996) The basic flow: an approach to calculate minimum environmental instream flows. Proceedings 2nd International Symposium on Habitat Hydraulics, Ecohydraulics 2000. Québec City, pp $547-558$

Portela, MM (2006) Definition of environmental flows in rivers of the south of Portugal. $8^{\circ}$ Congresso da Água Associação Portuguesa dos Recursos Hídricos. Figueira da Foz, 14 p. (In Portuguese)

Portela MM (2007) A hydrologic-hydraulic method to define ecological flows downstream dams located in South European semi-arid regions. 5th WSEAS International Conference on Environment, Ecosystems and Development. Tenerife, Spain, December 14-16, pp 329-334

Postel S, Richter B (2003) Rivers for life: managing water for people and nature. Island Press, Washington, DC

Richter BD, Warner AT, Meyer JL, Lutz K (2006) A collaborative and adaptive process for developing environmental flow recommendations. River Res Appl 22:297-318. doi:10.1002/rra.892

Santos JM, Ferreira MT (2008) Microhabitat use by endangered Iberian cyprinids nase Iberochondrostoma almacai and chub Squalius aradensis. Aquat Sci 70:272-281. doi:10.1007/s00027-008-8037-x

Stalnaker CB, Lamb BL, Henriksen J, Bovee KD, Bartholow J (1994) The instream flow incremental methodology: a primer for IFIM. National Ecology Research Center, internal publication. Fort Collins, Colorado, USA

Steffler P (2000) Software River2D: two dimensional depth averaged finite element hydrodynamic model. University of Alberta, Canada

Swales S, Harris JH (1995) The Expert Panel Assessment Method EPAM: a new tool for determining environmental flows in regulated rivers. In: Harper DM, Ferguson AJD (eds) The ecological basis for river management. Wiley, Chichester, pp 125-134

Tharme RE (2003) A global perspective on environmental flow assessment: emerging trends in the development and application of environmental flow methodologies for rivers. River Res Appl 19:397-441. doi:10.1002/ rra. 736

Vaze J, Jordan P, Beecham R, Frost A, Summerell G (2012) Guidelines for rainfall-runoff modelling: towards best practice model application. eWater CRC 